\title{
Le pôle sojicole sud-américain
}

\author{
Martine Guibert* \\ Équipe de recherche UMR CNRS 5193 LISST/Dynamiques rurales, Université Toulouse 2 - Jean Jaurès, Toulouse, France
}

Reçu le 16 novembre 2017 - Accepté le 18 décembre 2017

\begin{abstract}
Résumé - En Amérique du Sud, depuis une quarantaine d'années, le soja s'est imposé dans les régions rurales historiquement consolidées (Pampa argentine, Sud du Brésil, Ouest uruguayen, Est paraguayen) ainsi que dans les zones de fronts agricoles (Cerrado brésilien, Chaco argentin, Oriente bolivien). Il entre dans les schémas de double culture annuelle sur la même parcelle et il a accéléré le délaissement de la combinaison élevage-agriculture au profit d'une agriculture en continu. Ainsi, cinq pays se sont progressivement spécialisés dans la production de ce protéagineux : Brésil tout d'abord, Argentine et Bolivie ensuite, Paraguay et Uruguay enfin. Cependant, au-delà d'une apparente convergence sous-continentale, certaines modalités régionales et locales diffèrent. De plus, au côté des États-Unis, ces pays constituent l'autre grand pôle sojicole du continent américain, qui s'est à son tour rendu incontournable sur le marché mondial des quatre co-produits : graines, protéine, huile brute et biodiesel. En effet, si le Brésil possède un marché national conséquent, les autres pays produisent du soja pour l'exporter.
\end{abstract}

Mots clés : soja / Amérique du Sud / exportations / front agricole

Abstract - The South American soybean hub. For the last forty years, soybean has emerged in South America as the unavoidable crop production in both the historically consolidated rural areas (Argentine Pampas, Southern Brazil, Uruguayan West, and Paraguayan East) and the agricultural fronts (Brazilian Cerrado, Argentine Chaco, Bolivian Orient). Soybeans are systematically included in annual doublecropping patterns on the same plot and have accelerated the abandonment of the livestock-crop combination in favor of continuous farming. As time goes by, five countries have gradually specialized in the production of this protein crop: Brazil first, Argentina and then Bolivia, Paraguay and Uruguay finally. However, beyond an apparent sub-continental convergence, several different regional and local modalities exist. In addition, along with the United States, these countries are the other major agricultural hub of the American continent, which is indispensable in the global market for the four co-products currently generated, namely seeds, protein, crude vegetable oil and biodiesel. Although Brazil has a large domestic market to fulfill, other South American countries produce soybeans for export.

Keywords: : soybean / South America / exportations / agricultural fronts

\section{Introduction}

Alors que le soja était cultivé en très petites quantités à l'extrémité sud du Brésil ou en terre tropicale au nord-est de l'Argentine, sa production est d'importance depuis les années 1990 dans les plaines pampéennes tempérées des pays du Bassin du Río de la Plata (Argentine, Uruguay) et dans les terres tropicales de la Bolivie et du Paraguay. S'il occupe des superficies croissantes dans ces régions historiquement cultivées, il s'impose aussi sur des terres nouvellement mises en culture, issues de pâturages considérés comme dégradés et

*Correspondance : guibert@univ-tlse2.fr du défrichement du Bosque Atlántico del Alto Paraná au Paraguay, des forêts sèches du Chiquitano en Bolivie, des Yungas, du Chaco argentin, de la savane arborée du Cerrado au Brésil (Centre-Ouest) et, progressivement, de l'Amazonie (Carte 1). De "plante exotique », le soja est ainsi devenu la culture mono-spécifique la plus répandue dans ces régions sudaméricaines (Dougnac, 2013). Toutefois, si une certaine homogénéité se dégage à une échelle sous-continentale (modes de production, acteurs, etc.), l'exploitation du soja est fonction de caractéristiques locales souvent différentes, et de modalités distinctes quant à l'industrialisation et aux débouchés à l'exportation des sous-produits obtenus.

Le présent article rassemble des informations et des faits recueillis au cours de travaux de terrain effectués ces dernières 


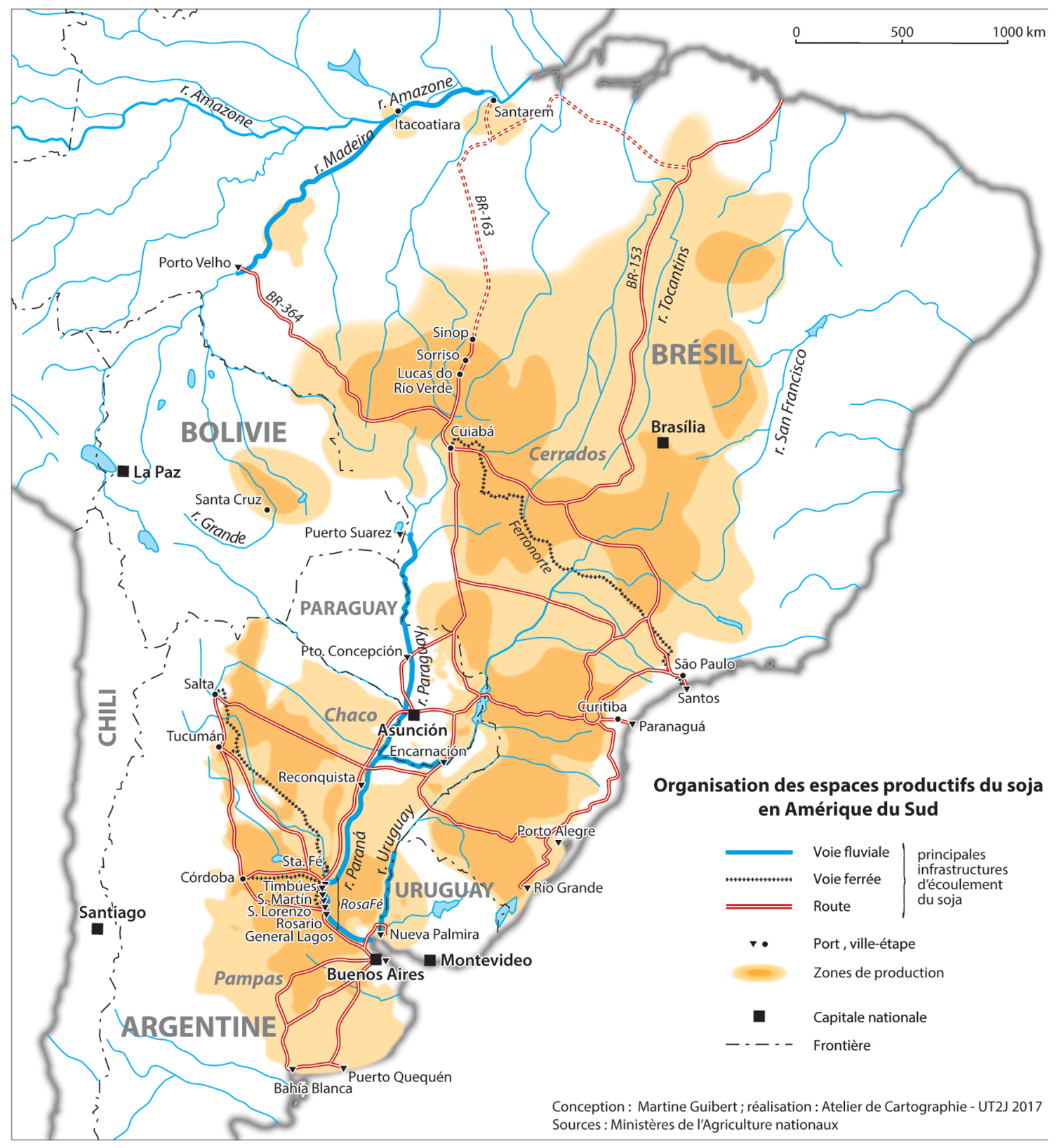

Carte 1.

années dans les pays concernés (sauf en Bolivie) et dans des publications scientifiques et/ou professionnelles, et ce grâce au soutien de programmes de recherche type Ecos et Cofecub. Notre approche est géographique et s'attache à mettre en évidence les différences socio-spatiales qui caractérisent l'évolution de la production de soja en Amérique du Sud.

\section{Une grande zone agricole sud-américaine}

Au gré de politiques publiques incitatrices et des stratégies des acteurs privés, chaque pays a développé sa filière soja selon des temporalités qui s'échelonnent depuis les années 1970, avec une accélération au cours des dernières années.
Au Brésil, c'est dans les États du sud (Río Grande do Sul et Paraná) que le soja a commencé à être cultivé au début des années 1950, en rotation avec le blé. À partir des années 1970, il devient une culture stratégique, à la fois sur un plan productif et commercial. Dans le cadre du PRODECER (programme de développement du Cerrado), il est au cœur de la mise en culture du Centre-Ouest qui, après déboisement de la savane arborée, va être organisé en fonction de la production de grains et, plus tard, de viande de bœuf et de viandes blanches (Adão et al., 2006; Bühler et Guibert, 2016). En à peine trente ans, la superficie a été multipliée par dix, passant de 1,3 million d'hectares semés en 1970, à 8,8 en 1980 (données de la CONAB citées par Pierri et Wesz, 2017), 11,6 en 1990 et 13,7 en 2000. Dix millions d'hectares se rajoutent durant la 
Tableau 1. Brésil : superficie semée en soja, maïs et blé, et plantée en canne à sucre (hectares).

\begin{tabular}{lrrrrr}
\hline Culture & \multicolumn{5}{c}{ Campagne agricole } \\
\cline { 2 - 6 } & $1989-1990$ & $1999-2000$ & $2009-2010$ & $2014-2015$ \\
\hline Soja & 11584734 & 13693677 & 23339094 & 32206387 & $2015-2016$ \\
Maïs & 12023771 & 12648005 & 12963080 & 15846517 & 2490115 \\
Blé & 3349956 & 1535723 & 2182667 & 16039474 \\
Canne & 4322299 & 4879841 & 9164756 & 16161622 \\
\hline
\end{tabular}

Source : IBGE-SIDRA.

Tableau 2. Brésil: production de soja, maïs, blé et canne à sucre (tonnes).

\begin{tabular}{lrrrr}
\hline Culture & \multicolumn{4}{c}{ Campagne agricole } \\
\cline { 2 - 5 } & $1989-1990$ & $1999-2000$ & $2009-2010$ \\
\hline Soja & 19897804 & 32820826 & 68756343 & $2014-2015$ \\
Maïs & 21347774 & 32321000 & 55364271 & 67464936 \\
Blé & 3093791 & 1725792 & 250 & 55284656 \\
Canne à sucre & 262674150 & 326121011 & 717463793 & 748636167 \\
\hline
\end{tabular}

Source : IBGE - SIDRA.

décennie 2000 (23,3 millions d'hectares semés en 2010) et presque autant durant les années 2010 (Tab. 1). En 2016, ce sont 33,3 millions d'hectares qui ont été semés en soja.

$\mathrm{Si}$ la région Sud était historiquement en tête, avec 10,5 millions d'hectares en 2014-2015, c'est désormais le Centre-Ouest qui est devant, avec près de 15 millions d'hectares, dont 8,9 dans l'État du Mato Grosso et 3,2 dans celui de Goías. Actuellement, les Cerrados du Centre-Nord (États du Maranhão, Piauí, Tocantins et Bahía, parfois appelés Mapitoba) sont les nouvelles aires d'expansion (voir Alves, 2015). Par comparaison, alors que la superficie dédiée au soja a triplé entre le début des années 1990 et le milieu des années 2010 , elle a été multipliée par 2,5 pour la canne à sucre, l'autre spéculation en forte progression et le maïs a gagné plus de 4 millions d'hectares (en deuxième récolte soja-maïs et hausse des rendements). Le coton reste également une culture importante et la double culture soja-coton est possible. Le blé, apanage des terres tempérées de l'extrémité sud du pays, a perdu plus de 1,2 million d'hectares.

La production de soja (Tab. 2) est passée d'une vingtaine de millions de tonnes au début des années 1990 à une centaine au milieu des années 2010. La canne à sucre a triplé ses volumes, le maïs les a quadruplés et le blé revient depuis les années 2000 .

En Argentine, après la phase d' «agriculturisation » de la région pampéenne des années 1960, la période des années 1990 a été aussi propice à une augmentation de la production et de la productivité. Ainsi, la superficie consacrée aux grandes cultures va passer de 20 millions d'hectares environ jusqu'au début des années 1980, à plus de 30 au milieu des années 2000. Elle atteint 38,8 millions d'hectares au milieu des années 2010 (sans compter les superficies en double culture annuelle). Si le soja est une culture quasi confidentielle dans les années 1950 (1000 hectares environ), il sera semé sur près de 80000 hectares en 1971-1972, 2 millions d'hectares en 1981-1982, 5, en 1989-1990, près de 9 en 1999-2000, plus de 18 en 2009-2010 et près de 20,5 millions d'hectares en 2015-2016 (Tab. 3). La superficie sojicole a donc quasiment doublé tous les dix ans. Actuellement, elle représente plus de la moitié de la superficie agricole en cultures annuelles de l'Argentine. Les autres productions de grains ont reculé, notamment le tournesol mais aussi le blé, le maïs restant une culture prisée.

Cet accroissement des superficies emblavées peut être expliqué par plusieurs facteurs. Tandis que la culture du soja se concentre dans les années 1940-1950 dans les provinces de Misiones et de Tucuman, l'impulsion de recherches par l'État et l'identification de débouchés possibles (Dougnac, 2013) vont motiver son extension au-delà de cette zone sub-tropicale. Depuis, le soja n'a eu de cesse de gagner la Pampa humide (nord de la province de Buenos Aires, sud de celle de Santa Fe et ouest de celle de Córdoba) et le nord-ouest du pays (provinces de Salta, Santiago del Estero, Tucuman). Sur les meilleures terres de la Pampa humide, en bordure du Paraná, les duos culturaux blé-soja, maïs-soja ou soja-soja (soja de segunda) sont possibles, moyennant un recours aux amendements et une rotation des assolements. Dans la Pampa plus sèche du sud-ouest, le soja a pris la place du tournesol ou de pâturages.

En Argentine, la hausse de la quantité de grains récoltés s'est accentuée dans les années 2000: 35 millions de tonnes à la fin des années 1980, 95 en 2009-2010 et plus de 125 en 2015-2016 (Tab. 4). Le soja représente près de la moitié de ce total (près de 59 millions de tonnes) ce qui montre sa fulgurante avancée dans ce pays historiquement producteur de blé. Le blé, justement, a été davantage récolté en 2015-2016 après des années 2000 difficiles en raison de l'application de droits à exporter, supprimés en 2016. Le maïs approche les 40 millions de tonnes en 2015-2016; il est préservé en raison de la double récolte maïs-soja, il bénéficie de la tonicité du marché et rentrera dans un avenir proche dans la fabrication croissante d'éthanol. Le tournesol a été relégué, sa production est de 2 à 3 millions de tonnes. 
Tableau 3. Argentine : superficie récoltée en soja, blé, maïs et tournesol (hectares).

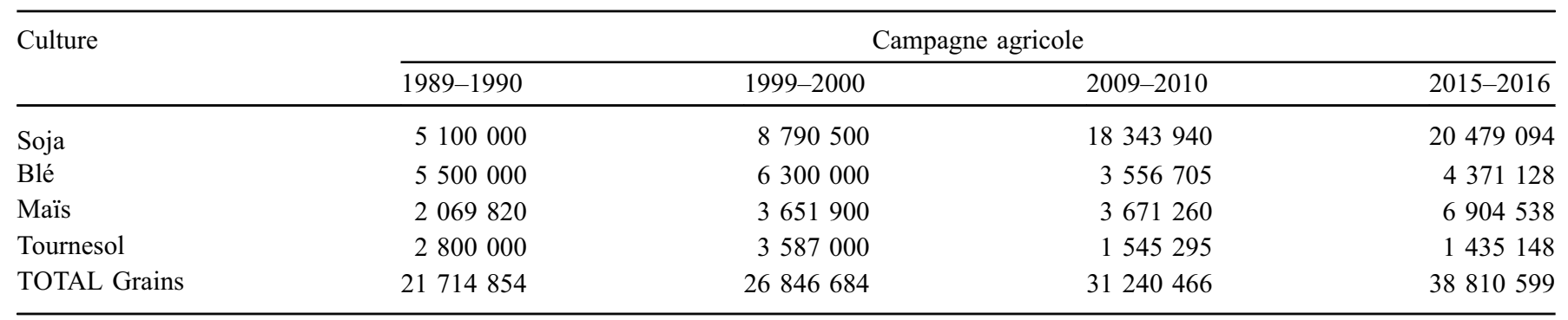

Source: Ministère de l'agro-industrie d'Argentine.

Tableau 4. Argentine : production de soja, blé, maïs et tournesol (tonnes).

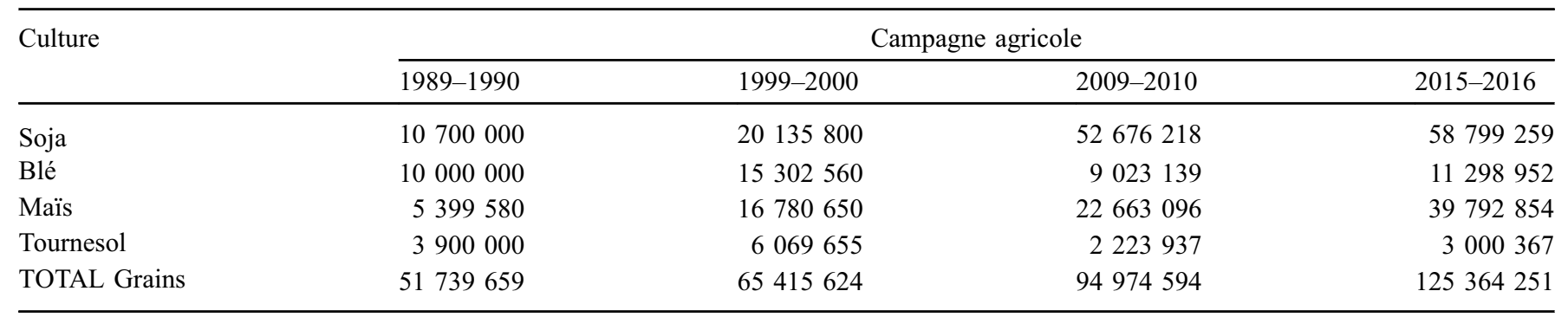

Source: Ministère de l'agro-industrie d'Argentine.

Tableau 5. Paraguay: superficie récoltée en soja, blé, maïs et tournesol (hectares).

\begin{tabular}{lccrrrr}
\hline Culture & \multicolumn{5}{c}{ Campagne agricole } \\
\cline { 2 - 6 } & $1979-1980$ & $1989-1990$ & $1999-2000$ & $2009-2010$ & $2015-2016^{*}$ & $2016-2017^{*}$ \\
\hline Soja & 475300 & 899900 & 1176460 & 2671059 & $3264480^{*}$ \\
Blé & 49200 & 156498 & 159342 & 560800 & $519185^{*}$ & $438709^{*}$ \\
Maïs & 226000 & 191000 & 331725 & 794034 & $838768^{*}$ \\
Tournesol & 1000 & 16000 & 70800 & 168103 & $30000^{*}$ \\
\hline
\end{tabular}

Source : FAOSTAT et ${ }^{*}$ CAPECO (Chambre paraguayenne des exportateurs et des négociants en grains).

Tableau 6. Paraguay: production de soja, blé, maïs et tournesol (tonnes).

\begin{tabular}{lrrrrr}
\hline Culture & \multicolumn{4}{c}{ Campagne agricole } \\
\cline { 2 - 6 } & $1979-1980$ & $1989-1990$ & $1999-2000$ & $2009-2010$ \\
\hline Soja & 537300 & 1794618 & 2980060 & 7460435 & $2015-2016^{*}$ \\
Blé & 83769 & 259337 & 220055 & 1401987 & $9216937^{*}$ \\
Maïs & 351000 & 420019 & 647270 & 3108821 & $4262918^{*}$ \\
Tournesol & 10000 & 23000 & 81950 & 262293 \\
\hline
\end{tabular}

Source : FAOSTAT et ${ }^{*}$ CAPECO (Chambre paraguayenne des exportateurs et des négociants en grains).

Au Paraguay, dans les années 1970, le gouvernement a organisé la colonisation des terres de l'Est. Dans les départements d'Alto Paraná, d'Itapúa, etc., le Bosque Atlántico a été déboisé souvent par les paysans et les migrants sans terre, avant l'installation d'agro-entrepreneurs brésiliens qui vont développer la culture du soja. Ensuite, durant la phase de mécanisation de la décennie 1990, le soja va s'imposer comme première culture du pays (Ferreira et Vázquez, 2015). Cette région de l'Est, frontalière du Brésil (départements d'Alto Paraná, Itapúa, Canindeyú, Caaguazú), concentre aujourd'hui la quasi-totalité de l'aire sojicole du pays. Si moins de 0,5 million d'hectares sont récoltés en 1980, ce sont 0,9 million en 1990 , près de 1,2 en 2000 et plus de 2,6 en 2010 (Tab. 5). Les 3 millions d'hectares sont maintenant dépassés, le soja étant loin devant le maïs et le blé. La production de soja avoisine les 3 millions de tonnes en 19992000 , près de 7,5 au début des années 2010 et 9,2 en 20152016 (Tab. 6). Les autres cultures de l'agriculture technicisée, telles que le maïs, le blé et le tournesol, sont également en forte progression. 
Tableau 7. Bolivie: superficie récoltée en soja, blé, maïs et tournesol (hectares).

\begin{tabular}{llrrr}
\hline Culture & \multicolumn{4}{c}{ Campagne agricole } \\
\cline { 2 - 5 } & $1979-1980$ & $1989-1990$ & $1999-2000$ & $2009-2010$ \\
\hline Soja & 37580 & 143372 & 616964 & 1086769 \\
Blé & 100370 & 84072 & 119538 & 173412 \\
Maïs & 293480 & 234696 & 307292 & 365354 \\
Tournesol & s/d & 10217 & 130000 & 177702 \\
\hline
\end{tabular}

Source : FAOSTAT.

Tableau 8. Bolivie: production de soja, blé, maïs et tournesol (tonnes).

\begin{tabular}{lcrrrr}
\hline Culture & \multicolumn{5}{c}{ Campagne agricole } \\
\cline { 2 - 6 } & $1979-1980$ & $1989-1990$ & $1999-2000$ & $2009-2010$ & $2013-2014$ \\
\hline Soja & 47595 & 232743 & 1197251 & 1693448 & 2878179 \\
Maïs & 383365 & 390952 & 653271 & 1018988 & 241397 \\
Blé & 60140 & 54480 & 101510 & 246683955 \\
Tournesol & s/d & 13973 & 110500 & 98699 \\
\hline
\end{tabular}

Source : FAOSTAT.

En Bolivie, les cultivateurs de l'Oriente (région des terres basses de l'est et de l'Amazonie) adoptent le soja tout aussi rapidement qu'au Paraguay (Colque, 2014). Entre le début des années 1990 et le milieu des années 2000, la superficie agricole du Département de Santa Cruz passe de 0,4 million d'hectares à 1,8 dont un million environ pour le soja et les autres oléoprotéagineux, et le reste pour les céréales. C'est alors près de $70 \%$ de la superficie cultivée totale du pays (Urioste in FAO, 2012). Les investissements nécessaires pour l'installation des cultures (déboisement, nivellement, traitements, etc.) sont réalisés majoritairement par des entrepreneurs d'origine brésilienne. L'avancée actuelle de la culture du soja dans le département est moins rapide, car moins de terres à « usage intensif » (selon la classification nationale des sols) restent disponibles. Au milieu des années 2010, plus de 1,2 million d'hectares ont été semés en soja sur un total de 2 millions d'hectares environ consacrés aux grains (Tab. 7).

Si l'on considère les volumes (Tab. 8), le soja est en tête de liste, avec près de 2,9 millions de tonnes en 2013-2014, contre près de 233000 tonnes vingt-cinq ans plus tôt.

En Uruguay, pendant la décennie 2000, les systèmes traditionnels des Campos (nom donné aux prairies tempérées, appelées également Pampas), avec une forte articulation entre céréales et troupeaux (bovins ou ovins selon la région), ont cédé la place aux plantations d'eucalyptus et au soja. Le pays entre alors dans une période d'intensification inédite de sa production agricole, élevage bovin compris. La filière forestière (eucalyptus pour la production de pâte de cellulose) attire des entreprises étrangères dans la production primaire et la transformation industrielle, et dans les filières viandes (rachat des installations d'abattage-découpe nationales). Concernant le soja, des producteurs argentins se sont installés en Uruguay et ont implanté le «modèle» du pool de siembra développé dans leur pays. Ces associations d'acteurs gèrent une ressource productive au nom de leur propriétaire: elles louent le foncier nécessaire à leur projet de production, elle lèvent des fonds avec rémunération du capital, parfois, sous forme actionnariale. Par ailleurs, elles confient les travaux agricoles à des entreprises spécialisées et un ingénieur agronome est chargé du suivi de l'ensemble des cultures (Guibert et al., 2015). Ces producteurs argentins ont été attirés par le bon niveau technique de l'agriculture uruguayenne, par des terres bon marché (par rapport aux loyers pratiqués chez eux) et considérées comme aptes à une production plus intensive, et par la stabilité juridique du pays (Errea et al., 2011). Très vite, le soja (mais aussi les plantations d'eucalyptus dans le cadre d'un autre modèle productif) va concurrencer le blé, le maïs, l'orge et le sorgho, ainsi que l'élevage bovin. Les 9000 hectares semés en 1999-2000 passent à 863000 hectares dix ans plus tard. Depuis le milieu des années 2010, le million d'hectares est dépassé, le soja occupant plus de $80 \%$ de la superficie agricole totale du pays (Tab. 9). Plus de $50 \%$ du soja uruguayen est semé dans la région agricole de l'ouest (départements de Soriano, Río Negro, Paysandú, Colonia) et, ensuite, dans des départements du centre (Durazno, Flores). Récemment, les entreprises argentines ont quitté l'Uruguay, suite à la hausse des coûts de production et à la baisse des prix du marché, mais des producteurs uruguayens ont repris à leur échelle et en partie leur modèle économique.

Au même titre que la superficie occupée, les volumes de soja produits sont sans commune mesure avec ceux des autres cultures (Tab. 10) : en 2015-2016, le soja représente 50\% du total des grains récoltés, contre moins de $40 \%$ au début de la décennie. La présence des autres grains n'est plus aussi prégnante, même si les rotations et la double culture les préservent en partie.

Dans les cinq pays latino-américains concernés par notre étude, les rendements se sont accrus du fait de l'amélioration des méthodes de production et de l'emploi croissant d'engrais, tout en sachant que la question de la reconstitution de la fertilité des sols est sérieusement posée. En Argentine, au Brésil et au Paraguay, en agriculture pluviale, les rendements en soja sont de niveau mondial, avec des taux moyens de 
Tableau 9. Uruguay: superficie semée en soja, blé, maïs et orge (hectares).

\begin{tabular}{|c|c|c|c|c|c|}
\hline \multirow[t]{2}{*}{ Culture } & \multicolumn{5}{|c|}{ Campagne agricole } \\
\hline & 1989-1990* & 1999-2000 & 2009-2010 & 2015-2016 & 2016-2017 \\
\hline Soja & $28500^{*}$ & 9000 & 863000 & 1160000 & 1089000 \\
\hline Maïs & $60677^{*}$ & 42300 & 96000 & 83000 & 66000 \\
\hline Orge & $\mathrm{s} / \mathrm{d}$ & 55000 & 141000 & 92000 & 190000 \\
\hline
\end{tabular}

Source : MGAP-DIEA (Ministère de l'agriculture, de l'élevage et de la pêche d'Uruguay - Direction des statistiques et des études agricoles) et *: FAOSTAT.

Le sorgho se maintient entre 50 et 70000 hectares et le tournesol a quasiment disparu.

${ }^{* *}$ : les superficies sont exprimées par produit, en incluant la double culture et pas les totaux pour l'ensemble des grains. La valeur de ces totaux est donc inférieure à la somme des quatre cultures.

Tableau 10. Uruguay: production de soja, blé, maïs et orge (tonnes).

\begin{tabular}{llrrr}
\hline Culture & \multicolumn{3}{c}{ Campagne agricole } \\
\cline { 2 - 5 } & $1989-1990^{*}$ & $1999-2000$ & $2009-2010$ & $2015-2016$ \\
\hline Soja & $37000^{*}$ & 7000 & 1817000 & 2208000 \\
Blé & $417400^{*}$ & 384000 & 1844000 & 1191000 \\
Maïs & $112313^{*}$ & 65000 & 529000 & 487000 \\
Orge & $\mathrm{s} / \mathrm{d}$ & 110000 & 464000 & 355000 \\
TOTAL Grains & $\mathrm{s} / \mathrm{d}$ & 619000 & 4802000 & 449000 \\
\hline
\end{tabular}

NB : Le sorgho se maintient entre 200 et 300000 tonnes. La production de tournesol a été divisée par deux à partir du milieu des années 2000 (80 000 tonnes) et a depuis quasiment disparu.

Source: MGAP-DIEA (Ministère de l'agriculture, de l'élevage et de la pêche d'Uruguay.

Direction des statistiques et des études agricoles) et ${ }^{*}$ : FAOSTAT.

3 tonnes par hectare environ (certaines parcelles dépassant les 4 voire les 5 tonnes par hectare). Pour le maïs, 6 à 7 tonnes sont récoltées par hectare (bien plus dans certaines exploitations) pour les deux premiers pays et 5 en moyenne au Paraguay. En Uruguay, ces valeurs sont légèrement inférieures mais elles sont meilleures en blé avec 3,5 tonnes par hectare en moyenne ces dernières années et le taux de 3 tonnes par hectare en soja devait être obtenu en 2016-2017. La Bolivie présente des rendements de l'ordre de 2,3 tonnes par hectare en soja en 2013-2014, autant pour le maïs et 1,7 pour le blé.

En 2015-2016, avec 165 millions de tonnes de fèves de soja récoltées dans les cinq pays considérés (dont plus de 95 au Brésil), l'Amérique du Sud représente plus de la moitié de la production mondiale. Elle constitue l'autre pôle oléoprotéagineux du continent, au côté des États-Unis (plus de 106 millions de tonnes). Le Canada se distingue pour le colza en fournissant plus de $28 \%$ de la production mondiale (Tab. 11).

\section{Des différences nationales}

Production-clé pour ces cinq pays d'Amérique du Sud, le soja a orienté la mise en culture des nouvelles régions, au détriment de certaines populations locales, impuissantes et peu considérées, et d'écosystèmes détruits ou fortement dégradés, et mal défendus par des codes forestiers dont l'application est difficile. Il façonne aussi les espaces agricoles consolidés qui, du coup, sont supplantés par ces nouveaux espaces dynamiques, qui ne sont plus à la marge. Partout, il est synonyme de conduite culturale simplifiée et de diminution des coûts de production, avec la combinaison semis direct, herbicides à base de glyphosate et semences génétiquement modifiées. Avec le changement climatique, l'heure est au test de nouvelles biotechnologies et à l'e-agriculture : cultivars spécifiques par région, traitements phytosanitaires ciblés après repérage par drone, suivi précis du comportement agronomique à l'échelle de la parcelle, etc.

Les autres grandes cultures (selon les régions : maïs, blé, orge, colza, tournesol, coton, canne à sucre) se maintiennent bon an mal an. Côté élevage bovin, des producteurs se lancent dans la fabrication d'aliments composés à base de soja et de maïs, ou de résidus d'autres grains (coton), de manière à les valoriser sur leur exploitation. Ils aménagent des ateliers d'engraissement (feed lots) de quelques centaines de têtes à plusieurs milliers, où les animaux restent durant la dernière phase de l'engraissement, après avoir été à l'embouche herbagère (parfois, ils sont élevés exclusivement en embouche industrielle).

Un ensemble d'acteurs, transnationaux, nationaux, locaux, alliés dans leurs stratégies d'accumulation et de contrôle des ressources, et sous la bienveillance des pouvoirs publics, développe ces productions dont celle de la chaîne de valeur 
Tableau 11. Évolution de la production (milliers de tonnes) de fèves de soja, de graines de tournesol et de colza au Brésil, en Argentine, au Paraguay, en Bolivie, en Uruguay, aux États-Unis et au Canada.

\begin{tabular}{|c|c|c|c|c|c|c|c|c|c|}
\hline \multirow[t]{2}{*}{ Pays } & \multicolumn{3}{|c|}{$2011 / 12$} & \multicolumn{3}{|c|}{$2015 / 16$} & \multicolumn{3}{|c|}{ 2016/17 (estimation) } \\
\hline & Soja & Tournesol & Colza & Soja & Tournesol & Colza & Soja & Tournesol & Colza \\
\hline Brésil & 67920 & 116 & 52 & 95435 & 62 & 77 & $114000^{*}$ & $96^{*}$ & $70^{*}$ \\
\hline Paraguay & 4043 & 79 & 98 & 9600 & 110 & 116 & $9800^{*}$ & $110^{*}$ & $120^{*}$ \\
\hline Bolivie & 2370 & 194 & - & 2700 & 125 & - & $2730^{*}$ & $45^{*}$ & - \\
\hline Canada & - & - & 14608 & - & - & 18377 & - & - & $19200^{*}$ \\
\hline TOTAL MONDE & 240979 & 39773 & 61424 & 311573 & 42465 & 64018 & $334310^{*}$ & $47397^{*}$ & $61142^{*}$ \\
\hline
\end{tabular}

- : valeur insignifiante; ${ }^{*}$ : estimation des Ministères nationaux.

Source: Annuaire 2017 Hinrichsen (Argentine) sur la base de données d'Oil World.

globalisée du soja. Ils suivent des protocoles de production technicisés et conçus pour de grandes extensions de foncier, mais aussi pour des petites et moyennes structures. Or, si les innovations, pour beaucoup d'origine étrangère ou pensées localement selon des référents globalisés, sont plébiscitées par les producteurs entrepreneuriaux et si elles semblent homogénéiser les processus, des considérations locales et nationales prévalent néanmoins.

Tout d'abord, de manière globale, non seulement le cadre normatif et l'action publique de chaque pays pèsent sur les stratégies de localisation et de développement, mais aussi les mouvements sociaux de résistance et de rejet de l'agriculture intensifiée : incitations ou blocages (fiscalité, investissement), règles du marché foncier, normes relatives à l'usage des pesticides, législation sur les semences, encadrement du transport, opinion publique. Selon les pays, les problématiques environnementales et sociales sont différentes. Ainsi, la conflictualité est plus forte dans le cas des espaces neufs (récemment dédiés aux grandes cultures ou à l'élevage), ce qui reflète des situations historiques et socio-culturelles non résolues, et une absence de régulation véritable de la propriété du foncier (manque de cadastres, titres de propriété déficients, spoliation, etc.).

Ensuite, la politique fiscale présente des dispositifs de taxations dissemblables d'un pays à l'autre. Ainsi, les gouvernements argentins successifs récents ont changé la politique de rétentions sur les exportations de matières premières : alors qu'elles avaient été annulées dans les années 1990, ils les ont rétablies et ont augmenté leur niveau dans les années 2000 et 2010, puis en partie supprimées depuis 2015 (sauf sur les co-produits du soja). A la même date est intervenue la libéralisation des droits à exporter qui entravaient les opérations commerciales avec les pays tiers. Les autres pays n'ont pas ce type de taxes; en revanche, ils pratiquent des politiques d'imposition plus lourde qu'avant. Par ailleurs, des mesures d'accès au crédit accompagnent les producteurs (pour le Brésil, voir Leite, 2015) avec des facilités accordées aux plus grands. Les capitaux externes sont attirés et moins contrôlés du fait de la dérégulation récente des économies.

Concernant l'adoption des semences génétiquement modifiées, les situations nationales diffèrent en partie. Si elles ont été introduites en Argentine durant la campagne agricole
1996/1997 et autorisées quasiment en même temps en Uruguay, elles n'ont été légalisées qu'au cours des années 2000 dans les autres pays (après des périodes de contrebande de semences venant d'Argentine). En 2016, le soja est génétiquement modifié quasiment à $100 \%$ partout dans la région, sauf au Brésil (plus de la moitié). Les centres de recherche public-privé à la pointe des dernières biotechnologies (Bioceres-Indear en Argentine, Fundação Mato Grosso au Brésil) et les semenciers privés offrent leurs dernières innovations. Selon l'ISAAA (International Service for the Acquisition of Agri-biotech Applications), en 2016, 12 cultivars transgéniques pour le soja sont approuvés par les autorités argentines, 11 au Brésil, 7 en Uruguay, 3 au Paraguay et 1 en Bolivie. La résistance de certaines plantes adventices et les effets sur la santé des populations de traitements aériens parfois réalisés au plus près des lieux habités ne freinent pas pour l'instant l'utilisation de ces semences et des intrants afférents.

Quant à l'encadrement des modes de faire-valoir, direct ou indirect, il change selon le contexte national, tout comme le contrôle de la vente des terres aux étrangers. Au Brésil, la loi sur le «statut de la terre» de 1964 pose les bases du marché foncier, avec la création d'un registre des propriétés (déclaration volontaire) et d'un cadastre géré par l'INCRA (Institut national de colonisation et de réforme agraire) fondé en 1970. La loi n 5709 de 1971, ratifiée en 2010, limite l'achat de terres par des étrangers mais il est possible de signer des contrats de vente, s'il n'y a pas transfert de plus de $50 \%$ de l'exploitation par le Brésilien propriétaire (Wilkinson in FAO, 2012). En Uruguay, la loi 18092 de 2007 autorisait les Sociétés Anonymes à acheter des terres mais elles devaient dire quels étaient les titulaires des actions nominatives. Depuis 2011, seules des sociétés nominatives peuvent acheter du foncier (Piñeiro in FAO, 2012). En Argentine, des propositions de lois tentent de limiter les achats par des acteurs étrangers, sans grande portée toutefois (Murmis et Murmis in FAO, 2012). Au Paraguay (Galeano in FAO, 2012) et en Bolivie (Urioste in FAO, 2012), les titres de propriété font très souvent défaut, ce qui alimente l'insécurité juridique. De plus, le marché foncier est peu réglementé. La situation est assez mal connue et l'annonce de mesures de régularisation peut stimuler les transactions, les possesseurs de terres s'en défaisant avant leur application. 
Les questions sur la préservation des sols sont récurrentes et suscitent de nombreuses échanges d'expériences et débats. L'Uruguay semblerait être le plus en pointe dans ce domaine, avec une loi qui oblige le producteur à déclarer l'assolement envisagé, et à laisser une couverture végétale après la récolte et à suivre de bonnes pratiques. Toutefois, la mise en œuvre et le contrôle de l'application de ces mesures restent difficiles.

D'autres différences existent entre pays en ce qui concerne la tertiarisation des travaux agricoles et le recours à la location de terres. En Argentine, dans les années 1960, les rares possibilités d'agrandissement avaient débouché sur une surcapitalisation en machines agricoles et un excédent de temps chez des exploitants familiaux. Ces derniers sont devenus des prestataires de service en travaillant à leur compte des terres louées auprès des grands propriétaires ou celles de petits et moyens producteurs insuffisamment mécanisés. La figure du contratista, entrepreneur de travaux agricoles qui se déplace de chantier en chantier avec sa maison roulante, est ainsi familière dans le paysage agricole pampéen argentin. Ces deux modes d'accès au foncier et au matériel agricole, sans le posséder, ont pris de l'ampleur tout au long des décennies, la législation ayant rendu plus flexible le marché de la location. Ainsi, la loi $n^{\circ} 22298$ de 1980 ramène la durée des contrats à trois ans (au lieu de cinq) et permet de renouveler le contrat "accidentel" (temporaire) sur la même parcelle. Elle précise les modalités de conduite des cultures et le nécessaire maintien de la qualité des sols. De même, en Uruguay, la loi n 14384 de 1975 sur la location foncière n'impose plus de durée minimale (fixée jusqu'alors à six ans) et laisse les parties décider. En Bolivie et au Paraguay, la location et la tertiarisation sont quasiment inexistantes. Au Brésil, ces pratiques ne sont pas répandues et une loi datant de 1960 établit l'imposition des transactions foncières locatives, limitant ainsi le marché (Folha de São Paulo, 2014). Elles concernent quasi exclusivement la canne à sucre, les sucreries-raffineries ayant besoin de s'assurer de leur approvisionnement en matière première. En revanche, le Brésil est à la veille d'autoriser une tertiarisation plus souple des taches productives dans tous les secteurs d'activité.

Enfin, les contrastes nationaux se révèlent également dans les débouchés de la production de graines. Le Brésil fait figure d'exception par la taille de son marché national : il utilise une grande partie de la protéine de soja dans ses élevages de porcins, de volailles et de bovins, et l'huile est très utilisée dans la cuisine brésilienne. Le pays est donc davantage exportateur de graines que de sous-produits, avec la Chine comme principal client. L'Argentine, le Paraguay et l'Uruguay exportent presque toute leur production vers l'Asie (Chine), le Moyen-Orient et l'Europe. La Bolivie et son industrie huilière approvisionnent les pays voisins (accords commerciaux dans le cadre de la CAN - Communauté Andine des Nations).

Des différences sont notables en ce qui concerne l'industrialisation de la production agricole. Ainsi, les huileries de soja au Brésil sont relativement petites et dispersées entre les zones de production et les lieux de consommation (unités d'élevage et villes). En revanche, en Argentine, les installations portuaires le long du fleuve Paraná sont connues pour réunir les usines de trituration et de fabrication de biodiesel les plus grandes et les plus modernes du monde, les capacités de stockage étant de plusieurs centaines de milliers de tonnes. Par exemple, en 2016, Molino Agro SA (port de San Lorenzo), Terminal 6 Industrial SA (port de San Martín) ou Renova SA (port de Timbúes) ont chacune une capacité théorique de trituration de 20000 tonnes par jour (Hinrichsen, 2017). L'unité de Cargill dans le terminal de Villa Gob. Gálvez peut traiter $13000 \mathrm{t} / \mathrm{j}$ et celle de LDC (terminal Gral Lagos) peut absorber $12000 \mathrm{t} / \mathrm{j}$. D'autres complexes peuvent triturer plusieurs milliers de tonnes par jour. Dès lors, l'Argentine exporte les trois co-produits du soja (tourteaux, huile et biodiesel) et peu de graines. Son biodiesel est acheté majoritairement par les États-Unis. Les graines produites en Uruguay et Paraguay sont exportées en l'état ou triturées dans les pays voisins. Tous ces produits sont acheminés par camion dans l'ensemble des cinq pays, un peu par train et par voie fluviale en Argentine et au Brésil.

\section{Conclusion}

Pour la campagne 2017-2018, dans le Cerrado au Brésil, la canne à sucre devrait grignoter des hectares sur le soja (pression des sucreries-raffineries pour installer des plantations sous le régime de l'intégration contractuelle ou en soustraitance). L'élevage bovin (embouche herbagère et/ou engraissement en parcs) prend de l'ampleur en Argentine et en Uruguay. Le blé et le maïs sont davantage cultivés en Argentine et en Uruguay (le colza aussi). En Argentine, depuis deux campagnes, le soja occupe moins d'hectares (en-deça des 20 millions d'hectares dépassés en 2015-2016). Mais ces variations sont pour l'instant peu significatives face à la solidité affichée par l'oléo-protéagineux et à l'autre culture en plein essor: le maïs.

Un fait, pour l'instant marginal, est à signaler : depuis peu, quelques acteurs en Argentine et en Uruguay souhaitent développer une production de soja non génétiquement modifié. Il est ici utile de rappeler que le soja certifié par la RTRS (Round Table for Responsible Soy) n'exclut pas le soja génétiquement modifié des échanges commerciaux internationaux car la certification porte uniquement sur des considérations environnementales et sociales. Or, un semencier argentin a communiqué en 2017 (Clarín) sur son projet de faire produire un soja non transgénique sur quelques dizaines de milliers d'hectares. Les semences seraient fournies à des agriculteurs engagés par contrat, le prix d'achat serait majoré, et la traçabilité et les débouchés assurés. Sur un plan cultural, une telle décision suppose de revenir à des méthodes agronomiques conventionnelles. L'un des plus grands producteurs uruguayens, en partenariat avec des semenciers, aurait la même intention. Les arguments avancés sont l'apparition de plantes résistantes aux herbicides à base de glyphosate, les réticences de l'opinion publique (notamment dans les pays acheteurs) et le souhait exprimé par les consommateurs de produits finaux obtenus sans utilisation de plantes génétiquement modifiés. Le fait que ce soit de grands opérateurs de la filière soja donne un sens particulier à l'annonce : quels vont être les producteurs qui vont se lancer? quelle vont être les conditions de mise en place de cette production et les modalités de son suivi sur un plan logistique et réglementaire? quelle sera son ampleur dans un avenir proche? 


\section{Références}

Adão J, Freire Filho OL (org). 2006. Geografias da soja: BR-163. Fronteiras em mutação. Rio de Janeiro: Arquimedes.

Alves VEL (org). 2015. Modernização e regionalização nos Cerrados do centro-Norte do Brasil: Oeste da Bahia, Sul do Maranhão e do Piauí e Leste do Tocantins. Rio de Janeiro : Consequência.

Bühler EA, Guibert M, Oliveira VL (org). 2016. Agriculturas empresariais e espaços rurais na globalização. Abordagens à partir da América do Sul. Porto Alegre: Ed. UFRGS.

Clarín. 2017. La producción de soja no transgénica viene creciendo a buen ritmo en la Argentina, 28 avril.

Colque G. 2014. Expansión de la frontera agrícola. Luchas por el control y apropriación de la tierra en el Oriente boliviano. La Paz: Tierra.

Dougnac MG (comp.). 2013. De especie exótica a monocultivo. Estudios sobre la expansión de la soja en Argentina. Buenos Aires: Imago mundi.

Errea E, Peyrou J, Secco J, Souto G. 2011. Transformaciones en el agro uruguayo. Nuevas instituciones y modelos de organización empresarial. Montevideo : UCU.

FAO. 2012. Dinámicas en el mercado de la tierra en América Latina y el Caribe. Concentración y extranjerización. Avec Murmis M et
Murmis MR, "El caso de Argentina", pp. 1-42 ; Urioste M, "El caso de Bolivia", pp. 59-104 ; Wilkinson J, Reydon B, Di Sabbato A, "El caso de Brasil", pp. 105-143 ; Galeano LA, "El caso de Paraguay", pp. 407-434 ; Piñeiro D, "El caso de Uruguay", pp. 521-552.

Ferreira M, Vázquez F. 2015. Agricultura y desarrollo en Paraguay. Asunción: UGP.

Folha de São Paulo. 2014. Aluguel de terra é reduzido no Brasil e limita a produção, 25 juin.

Guibert M, Requier-Desjardins D, Bühler EA. 2015. Agricultures d'entreprise et globalisation des espaces ruraux. Éclairages à partir de l'Argentine, du Brésil et de 1'Uruguay. G.E.S. 4: 433458.

Hinrichsen, Annuaire 2017 des industries de la trituration en Amérique latine.

Isaaa, Anual report 2016, en ligne.

Leite Pereira S. 2015. État, politiques publiques et agribusiness au Brésil : une analyse de la politique de financement agricole actuelle. G.E.S. 4: 433-458.

Pierri J, Wesz Jr WJ. 2017. La sojización en Argentina y Brasil (1980/ 2014): influencia de las políticas públicas, de las empresas transnacionales y de la estructura económica dependiente, Extensão rural, DEAER-CCR-UFSM, 1, 20-41.

Citation de l'article : Guibert M. 2018. Le pôle sojicole sud-américain. OCL 25(1): D103. 